\title{
Murtaza'yı Toplumsal Sorunların Belirtisi Olarak Okumak ve İzlemek
}

\author{
DOI: $10.26466 /$ opus. 517860 \\ *
}

\section{$\underline{\text { Aydın Çam }}$}

\author{
* Dr, Öğr. Üyesi, Çukurova Üniversitesi İletişim Fakültesi, Sarıçam / Adana / Türkiye \\ E-Posta: aydinaksu@gmail.com \\ ORCID: $\underline{0000-0002-4168-3093}$
}

\section{Öz}

Bu çalışmada Orhan Kemal'in ilk olarak 1952 yılında Vatan Gazetesi'nde tefrika edilen ve aynı yıl Varlık Yayınları'ndan kitap olarak çıkan Murtaza adlı romanı ve bu yapıttan Tunç Başaran'ın Bekçi Murtaza (1965) ve Ali Özgentürk'ün Bekçi (1985) adıyla gerçekleştirdiği uyarlamalar, Murtaza tiplemesi merkeze alınarak soruşturulmaktadır. Murtaza, ilhamını 1950'li yıllarda sanayileşmeyle birlikte büyük dönüşümler yaşayan Adana'dan alan romanın kahramanıdır ve söz konusu dönüşümlerden mustariptir. Yaşadığı mekâna, zamana ve topluma uyum să̆layamayan, yabancılaşmış biridir. Çalışmada roman ve romandan yapılan uyarlamalar, edebiyat ve sinema ile hekimlik arasında yöntemsel bir ilişki kurularak çözümlenmektedir. Edebiyatçılar ve sinemacılar, topluma tıpk bir hekimin hastalı̆̆a yaklaştığı gibi bakabilir. Bir yazar ya da yönetmen semptomatoloji, etiyoloji ve terapi etkinlikleriyle hastalı̆̆ın belirtilerini izleyebilir, toplumsal sorunları teşhis edebilir, hastalı̆̆ın nedenlerini saptayabilir ve bir tedavi önerebilir. Bu yöntemle beraber çalışmada, özellikle filmlerin soruşturulması için bağlamsal film çözümlemesi yönteminden yararlanılmıştır. Çalışma sonucunda Murtaza'nın çelişkilerle dolu karakterinin ve yaşamının aslında kapitalist sanayileşmenin dönüşümüyle açı̆̆a çıkan toplumsal sorunların belirtileri olduğu görülmüş̧tür. Orhan Kemal, Tunç Başaran ve Ali Özgentürk, Murtaza aracilğ̆ılala toplumsal sorunların yol açtığı hastalıkları teşhis etmektedirler. Bununla beraber, her ne kadar bu yapıtlarda bir tedavi önerilmese de toplumun sağaltımına dair olasıllkların önü de kapatılmaz.

Anahtar Kelimeler: Bekçi Murtaza, Toplumsal Tipler, Gilles Deleuze ve Sinema, Sinema ve Edebiyat 


\title{
Reading and Watching Murtaza, As a Symptom of the Social Problems
}

\begin{abstract}
In this study, Orhan Kemal's novel Murtaza, which is firstly published serially by Vatan Newspaper in 1952, later published as a book by Varlik Publishing House in the same year; and two films adapted from the novel, Tunç Başaran's Bekçi Murtaza (Murtaza the Watchman, 1965), and Ali Özgentürk's Bekçi (The Watchman, 1985) are inquired by focusing on Murtaza stereotype. Murtaza is the fictitious character of the novel, inspired by Adana city that seriously transformed by industrialization in the 1950s, and he is also a victim of these changes. He is an alienated person, who cannot accommodate the space and time, and cannot fit into society. In the study, the novel and the adaptations are analysed by making a methodological contact with literature, cinema, and medical sciences. Litterateurs and filmmakers can investigate the society just as a doctor diagnoses the diseases. An author or a director may watch the disease symptoms, identify the problems, diagnose the social diseases, and give therapy recommendations by following the symptomatology, etiology, and therapy practices. In addition to this, the contextual film analyse method is also used in the study, especially for adaptations. Following the analyses, it is appeared that the anomalous character and inconsistent life of Murtaza, is actually the symptom of social problems, which is formed by transformations of capitalist industrialization. Orhan Kemal, Tunç Başaran, and Ali Özgentürk diagnose the social diseases by Murtaza. And even though there aren't any therapy recommendations given by author and/or directors in their works, there is still a possibility for the therapy of society.
\end{abstract}

Keywords: Murtaza the Watchman, Social Stereotypes, Gilles Deleuze and Cinema, Cinema and Literature 


\title{
Giriş
}

\section{Murtaza Tiplemesi ve Adana'nın Kısa Sanayi Tarihi}

\author{
"Orhan Kemal, Yaşar Kemal'in de belirttiği gibi, \\ Murtaza'yı ölümsüzleştirmiştir. Şu da bir gerçek ki, \\ Murtaza da Orhan Kemal'i ölümsüzleştirecektir" \\ (Binyazar, 1970, s. 279).
}

Orhan Kemal'in, ilk olarak 1952 yılında Vatan Gazetesi'nde tefrika edilen ve aynı yıl Varlık'tan yayımlanan romanına adını veren Murtaza, bir insan tipine özgü tuhaflıklarıyla birlikte, bir toplumu ve dönemi temsil etme gücüyle de sıradan karakterlerden ayrılır. Bu, daha çok bireysel alanla sınırlandırılan karakter özelliklerini aşan bir durumdur. Üstelik Murtaza için temsilin sınırları öylesine geniştir ki sadece belli bir coğrafyaya veya döneme de özgü değildir. Murtaza evrensel bir tiptir ve hatta Yaşar Kemal'in (9 Haziran 1970) ifadesiyle "edebiyatın en ilginç tiplerinden biri, gerçekten ölmez tiplerinden biridir". Bununla beraber Murtaza, toplumsal bir tiptir. Toplumsal tipler bir coğrafyayı, bir dönemi ya da bir insan topluluğunu anlamamızı sağlayan öğelerdir ve sadece edebiyata özgü değildir. Örneğin filozoflar ya da sosyal bilimciler için toplumsal tipler, çözümlemelerinin merkezinde yer alan öğelerdendir. Çünkü bu öğelerin değişimlerden, dönüşümlerden ya da karşılaşmalardan sonra ortaya çıan toplumsal çatışmaları, sapkınlıkları, tuhaflıkları ya da hastalıkları açığa çıarma gücü vardır. Ve tıpkı filozoflar ve sosyologlar gibi edebiyatçlar da topluma bu tiplerle bakabilirler. Hatta bu yüzden edebiyatçların adları, bireysel ve/veya toplumsal psikolojik aykırılıklarla, sapkınlıklarla, hastalıklarla ya da bunalımlarla hep yan yana anılmıştır: Marquis de Sade'ın adını verdiği sadizmi ya da Leopold von Sacher-Masoch'nun adıyla anılagelen mazoşizmi istisna değildir; edebiyat tarihi benzer sapkın ya da anormal eşleşmelerle doludur. Gilles Deleuze, sadizm ve mazoşizm gibi pekâlâ Nietzcheizm, Proustizm, Kafkaizm, ya da Spinozizm gibi klinik kavramların ortaya çıabileceğini, çıkması gerektiğini ileri sürmektedir. Deleuze, buradan hareketle edebiyatçıların sapkınlık ya da aykırılıkla olan yakın ilişkisini, yazma eylemini de dâhil ederek şöyle açılar: "Kişi kendi nevrozlarıyla yazmaz. Nevroz, psikoz; bunlar yaşam geçitleri değil, süreç kesintiye 
uğradığında, engellendiğinde, tıkandığında içine düşülen durumlardır (...) Bu haliyle yazar da hasta değil, daha ziyade hekimdir, kendinin ve dünyanın hekimidir. Dünya, hastalığın insanla karşılaştığı semptomlar bütünüdür" (Deleuze, 2013, s. 12). İşte bundan dolayıdır ki, hemen her büyük edebiyatçı, dünyanın sapkınlıklarından ve aykırılıklardan mustarip bir de tip yaratmıştır; toplumsal sorunların belirtileri bu tiplerle görünür hale gelir. Daha roman sanatının ilk örneğinde bile bu durum görülür: Miguel de Cervantes'in Don Quijote'u vardır. Franz Kafka'nın tipi Joseph K.'dır; Herman Melville'in ise tipleri vardır: Kâtip Bartleby ve Kaptan Ahab. Fyodor Dostoyevski bize Raskolnikov'u takdim eder, Ivan Gonçarov ise Oblomov'u karşımıza çıkarır; Robert Musil'in Niteliksiz Adam'ı, Oğuz Atay'ın Tutunamayanlar'1, Yusuf Atılgan'ın Aylak Adam'ı, Ahmet Hamdi Tanpınar'ın Halit Ayarcı ve Nuri Efendi'si... Bütün bu tiplerin tıpkı Karl Marx'ın proleteri, Georg Simmel'in yabancısı ya da C. Wright Mills'in beyaz yakalısı gibi toplumsal karşılıkları vardır ve dahası bu tipler de ekonomik, politik, kültürel ve toplumsal sorunları işaret ederler.

Roman anlatısı içinde Murtaza'nın 1950'li yılların Adana'sında yaşadığını ve bir dönem Orhan Kemal'in de çalıştığı Millî Mensucat Fabrikası'nda bekçilik yaptığını öngörebiliriz. Bu yıllar Adana'nın büyük bir dönüşüm geçirdiği yıllardır. Şehir, sanayileşme süreciyle birlikte, Cumhuriyet döneminin ilk anakentlerinden biri olarak 1940'lardan itibaren hızla büyür. 1900'lerin başında Aristidi K. Simyonoğlu tarafından Simyonoğlu Fabrikası adıyla kurulan, 1927'de millileştirilerek faaliyetine devam eden Millî Mensucat Fabrikası, sanayinin lokomotifi konumundadır. Millî Mensucat Fabrikası'yla beraber 1937'de faaliyete geçen Sümerbank'in Adana Bez Fabrikası, Adana Pamuk Satın Alma ve Çırçır Fabrikaları gibi pek çok iştiraki de şehirde yerini alır. Adana artık kapitalist sanayileşmenin Anadolu'daki merkezlerinden biri durumundadır. Devletin girişimlerini özel sektöre bağlı irili ufaklı onlarca çırçır ve iplik atölyesi izler (Özcanl1, 2008, s. 157). Sanayileşme, 1948 'de Truman Doktrini ve Marshall Planı'nın ilanı, 1950'deyse Demokrat Parti'nin iktidarı devralmasıyla ivme kazanır. Bu ivmeyle Adana'ya çok sayıda tarım ve tarıma dayalı sanayide kullanılacak araç-gereç girişi olur. 1951'de PAKSOY Ticaret ve Sanayi A.Ş., 1953'te Güney Sanayii ve Ticaret A.Ş. faaliyete geçer. 1956'da BOSSA Ticaret ve Sanayii A.Ş. ve Akdeniz Tekstil Sanayii Fabrikaları ku- 
rulur. Bunu SASA Suni ve Sentetik Elyaf Sanayi A.Ş. takip eder. Aynı yıllarda şehrin genişlemesine bağlı olarak inşaat malzemesi üreten fabrikalar faaliyete geçer. 1954 'te kurulan Çukurova Çimento Sanayi T.A.Ş. ve Çukurova Makine İmalat ve Ticaret A.Ş., alanlarındaki en büyük işletmelerdendir. Sanayileşen şehirde işgücüne talep yüksektir ama sadece fabrikalar için değil, henüz bütünüyle makineleşmemiş tarımsal üretim, özellikle pamuk üretimi nedeniyle de tarım işçisi istihdamına yoğun talep vardır. 1940'tan sonra ekimi yapılan, yüksek verimli ancak çok kısa sürede toplanması gereken akala pamuğu üretimi nedeniyle çok sayıda mevsimlik tarım işçisi Adana'ya yönelir (Hinderink \& Kıray, 1970). Diğer yandan, tarımda makineleşmenin başlamasına koşut biçimde köylerden şehir merkezine yoğun hareket vardır (Yaman, 1981, s. 65). Gerek sanayii kolunda gerekse hammaddeyi sağlayan tarım arazilerinde işgücüne talep arttıkça şehrin nüfusu da artar. Ağırlıkla Çukurova Bölgesinden kaynaklanan yoğun göç nedeniyle şehrin nüfusu 1965'te yaklaşık 402.000'i merkezde, 480.000'iyse köylerde yerleşmiş bulunmak üzere, 902.000 kişiye ulaşır (TÜIK, 1965 Genel Nüfus Sayımı Veri Tabanı). Üstelik bu dönemde şehre göç edenlerin \%77,42'si ücretli olarak çalışmaktadır (Yaman, 1981, s. 112). Toplumsal tip olarak Murtaza, şehirdeki bu son derece devingen dönüşümle birlikte var olur.

\section{Araştırmanın Amacı, Temel Varsayımları, Araştırma Soruları ve Yön- temi}

Gilles Deleuze (2013, s. 13), “edebiyatın nihai amacı, [dünyaya dair] sabuklamanın içinden sağlık yaratımını ya da bir halkın keşfini, yani bir yaşam olasılığını ortaya çıkarmaktır," der. Onun bu önermesini tüm sanat etkinlikleri için genellemek mümkündür. Bunu sanatçıya zorlu bir görev yükleyen ve bir bakıma sanatın işlevleri hakkında ahkâm kesen bir üst bakış olarak görmemek gerekir. Elbette ekonomik, politik, kültürel ve toplumsal süreçlerden bağımsız ya da bütün bu süreçlerin dişında kalmaya çalışan bir sanat da olasıdır. Ancak tüm bu süreçlerden yalıtılmış bir sanat eseri, sanat tarihinde bir istisna olarak kalacaktır. Dünya bir semptomlar bütünü ve yazar da dünyanın bir hekimidir (Deleuze, 2013, s. 12); pekiyi yazarın belirtileri değerlendirmesini, teşhis koymasını ve tedavi önerme- 
sini, yani kelimelerle yaptığını ressamlar çizgiler ve renklerle, müzisyenler seslerle ve sinemacılar imgelerle yapamazlar mı? Şöyle soralım; edebiyatçıların ya da sosyologların yaptığı gibi, ekonomik, toplumsal, kültürel ve politik sorunlara işaret eden, dünyanın sapkınlıklarından ve anomalilerinden mustarip tiplerle beyaz perdede de karşılaşmıyor muyuz? Sinemacılar da yeri geldiğinde toplumsal karşlığı olan böylesine güçlü tipler yaratmış değil midir? Tabii ki yaratmışlardır. Tıpkı edebiyatçılar gibi, sinemacıların da tipleri vardır: Charles Chaplin, Şarlo'yu; Orson Welles, Charles Foster Kane'i; François Truffaut, Antoine Doinel'i; Stanley Kubrick, Alex DeLarge'1; Martin Scorsese, Travis Bickle'1 ve Michael Haneke, -çeşitlemeleriyle birlikte- Georges ve Anne'yı sunar. Pek çok büyük yönetmen tıpkı edebiyatçıların ve sosyologların toplumsal tiplerine benzer şekilde tipler yaratmış ve sinemalarında bu tiplerle birlikte dünyanın sapkınlıklarını ve aykırılıklarını irdelemişlerdir. Nihayetinde "sanatçılar [da] birer klinisyendir, kendi vakalarına ya da genel olarak herhangi bir vakaya ilişkin olarak değil, medeniyetin klinisyenleridir" (Deleuze'den aktaran Smith, 2013, s. 17). Tüm bu varsayımlardan sonra biz, Tunç Başaran'ın Bekçi Murtaza (1965) ve Ali Özgentürk'ün Bekçi (1985) adlı uyarlamalarıla birlikte Bekçi Murtaza romanı ve özelikle Murtaza tiplemesi için ne söyleyebiliriz? Deleuze'ün önermelerini göz önünde bulundurursak, Bekçi Murtaza yazıldığı ya da filme aktarıldığı dönemlerde hangi toplumsal tipe karşlık gelmekte ve hangi toplumsal problemin belirtilerine işaret etmektedir?

Deleuze için her edebiyat yapıtı bir yaşam tarzını, bir yaşam biçimini ifade eder ve hem kritik hem de klinik açıdan değerlendirilmelidir. Deleuze, bu önermesi için hekimlikten ilham alarak şöyle bir yöntem sunar: "Kritik ve Klinik, yani edebiyat ve tıp arasındaki ilişki semptomatolojik metodun özgün doğası vesilesiyle kurulur. Bu alandaki çözümlemeler üç farklı etkinlikten oluşan aşamalarla gerçekleştirilir: Semptomatoloji ya da belirtilerin tetkiki; etiyoloji ya da nedenlerin tespiti ve terapi, yani bir tedavinin geliştirilip uygulanması süreci" (Deleuze'den aktaran Smith, 2013, s. 13, 15). Buradan hareketle edebiyat ve sinemanın da Murtaza gibi tipler aracılığıyla toplumsal problemlerin belirtilerini belirleyerek bu problemleri teşhis edebileceğini, problemlerin nedenlerini saptayabileceğini ve bir tedavi önerebileceğini varsayabiliriz. Bu önermeleri sınamak ve özellikle romandan uyarlanan iki filmi çözümlemek için çalışmada, 
film çözümleme yöntemlerinin temel yaklaşımlarından olan bağlamsal (contextual) film çözümleme yöntemi kullanılmıştır. Bağlamsal film çözümleme yöntemini şu şekilde özetleyebiliriz: Bir filmde anlam öbekleri, genel geçer ifadeyle dilsel öğelerle ya da fizikî evrene benzerliklerden kaynaklanan durumlarla yani temsille oluşabilir. Bununla beraber bu öbekler, imgeler ya da örneğin duyular aracılığıyla da kurulur ve tüm bunları yorumlamak ancak sinemaya özgü kavram setlerini ve yöntemleri kullanmakla mümkündür. Film çözümleme yöntemleri genellikle biçimsel (textual) ve bağlamsal olarak ikiye ayrılır çünkü sinemasal anlam üretiminin yapısı iki boyutludur: Anlamın ilk boyutu bilinçli olarak tasarlanmış ve kısıtlıdır; yönetmen anlam üretiminin merkezinde bulunarak, sinemasal tüm araçları kullanarak bir anlam üretimine girişir. Bu, film yapımına ait yöntemlerin, tekniğin ve araçların kullanılmasıyla hem öykünün hem de anlamın gerçekleştirilmesi biçiminde meydana gelir. Anlamın bağlamsal boyutu ise genellikle bilinçli bir biçimde tasarlanmamıştır. Çoğu zaman yönetmen, öyle yapma niyetinde olmasa dahi, fizikî evrene dair pek çok öğeyi de filme taşır. En genel ifadeyle biçimsel çözümleme filmi gerçekleştirmeyi mümkün kılan öğelerin ve öğeler arasındaki ilişkilerin düzenlenmesiyle ilgiliyken, bağlamsal çözümleme filmle fizikî evren arasinda kurulan bağlarla ilgilidir (Phillips, 2000; Elsaesser \& Buckland, 2002; Barsam \& Monahan, 2010; Corrigan \& White; 2012; Nelmes, 2012; Ryan \& Lenos, 2012). Bu çalışmada, Murtaza romanı ve romandan yapılan uyarlamaların işaret ettiği toplumsal problemler, bu problemlerin belirtileri ve eğer varsa yazarın ve/veya yönetmenlerin çözüm önerileri, bağlamsal film çözümleme yöntemiyle yorumlanmaktadır.

\section{Araştırma Bulguları ve Değerlendirmeler: Toplumsal Dönüşüm Karş1- sında Çelişkilerle Dolu Bir Tip Olarak Murtaza}

“Orhan Kemal'in Murtaza'sı edebiyatımız içinde ilgi çekici bir örnek olma üstünlüğünü taşır. Adeta Türk romanında tipten karaktere geçişin -o yapılması şart olan aşamanın- ürünüdür. Orhan Kemal tipin ancak karakter olunca bir romanconın kişiliğini yansittığını bu eseriyle belirtmiştir" (Hızlan, 9 Haziran 1970).

Sadece Murtaza değil, Orhan Kemal'in diğer yapıtlarını yazdığı yıllar, Çu- 
kurova' da değişen ekonomik yapıyla birlikte dönüşümlerin yaşandığı yıllardır. Geleneksel kapitalist ilişkilerin yerini yeni kapitalist ilişkiler almıştır. Bununla beraber bölgede tarımsal üretim artmış ve tarımsal ürünün işlendiği sanayi işletmeleri yoğunlaşmaya başlamıştır. Çukurova'nın ve yakın bölgelerin kırsal kesimlerinde yaşayan insanlar şehir merkezlerine doğru harekete geçmiş, bununla birlikte toplumsal ilişkilerde farklı ölçeklerde dönüşümler yaşanmaya başlamıştır. Bunlar küçük ya da büyük, yapısal dönüşümlerdir. Farklı ölçeklerde yaşanan ama bir biçimde bireyi ve onun içinde yer aldığı toplumu ilgilendiren, geleneksel yapıda değişimlere, dönüşümlere ve çoğu zaman da çatışmalara yol açan çözülmelerdir. Tüm bu çözülmelere bağlı olarak da yeni insan tipleri ortaya çıkar. Orhan Kemal'i Türk edebiyat tarihinin köşe taşlarından biri yapansa bu çözülmeleri ve tipleri saptamada ve aktarmadaki olağanüstü gücüdür. Üstelik Murtaza, salt tahayyül edilmiş bir tip de değildir. Roman anlatısının d1şında, Murtaza'nın gerçekten yaşayıp yaşamadığına ve eğer yaşadıysa kim olduğuna dair farklı söylenceler vardır: Örneğin Orhan Kemal'in yaşamına tanıklık eden Nurer Uğurlu (1973, s. 209), Murtaza'nın Adana'daki bir Akbank şubesinde kapıcı olduğunu aktarır. Uğurlu ve yazarın eşi Nuriye Ögüttçü, Murtaza'yı bizatihi tanıdıklarını ifade etmektedir. Orhan Kemal'in keskin gözlemciliğini ve kendisine atfedilen "Ben tanıdığım insanları yazdım," şeklindeki ifadesini de düşündügümü̈zde, Murtaza'nın gerçekliğinden şüphe etmek yersiz olacaktır. Zaten Yaşar Kemal de, Murtaza'yla hem de Orhan Kemal aracılığıyla tanışmış kişilerdendir. Murtaza'yı yazmaya başladığı günlerde Orhan Kemal, Yaşar Kemal'i de yanına alıp onu görmeye gider. Yaşar Kemal (9 Haziran 1970) tanışma faslını şöyle aktarmaktadır: "Murtaza ile konuşmaya başladık, birdenbire Murtaza, 'A be efendiler,' dedi, 'beni tanır mısınız? Ben Bekçi Murtaza'yım, görmüşüm sıkı kurs, almışem âmirlerimden disiplin.'”

Murtaza, Cumhuriyet'in ilanından sonraki mübadelelerde Yunanistan'dan kardeşi ve annesiyle birlikte göç etmiş bir muhacirdir. Göç ettiğinde henüz yirmili yaşlarındadır. Diğer pek çok muhacirin aksine, kendisine telkin edilen ögütlere aldırmamış, hile yapmamış ve bu nedenle de konaklara, tarlalara konmamış biridir. Çünkü kendi ifadesiyle, Kolağası Hasan Bey'in soyundan gelen biri için esas olan namdır, şandır; mal ya da mülk değil. Çukurova'da on dönümlük bir araziyi yoksul annesi ve kar- 
deşiyle ekip biçmeye çalışmış ancak yukarıda da bahsettiğimiz dönüşümlere yenik düşmüş ve önce gece sokaklarda sonra da bir fabrikada bekçilik yapmaya başlamıştır. Şair, yazar ve araştırmacı Şükran Kurdakul (1983, s. 4), Orhan Kemal'in romanlarına aralarında Murtaza'nın da olduğu, toplumsal dönüşümün ezip geçtiği bu kişilerin yaşam serüvenlerinin egemen olduğunu ifade etmektedir. Kent ve köy emekçilerini temsil eden bu kişilerin varlıkları, ekmek kavgaları ve yaşadıkları olaylarla insansal değerlerin alınıp satılmak istendiği bir düzenin bireyleri olduklarını vurgular. Aslında Kurdakul'un tarif ettiği tip, dönüşüme direnmeyip ona uyum sağlayan ve kurulmakta olan düzen içinde yolunu bulan tiptir. Bu tip, bir Orhan Kemal senaryosundan Halit Refiğ tarafindan sinemaya aktarılan Gurbet Kuşları'nda (1964) karşımıza çıkan Haybeci'dir. Haybeci üçkâğıtçı, dalavereci, kendinden üstte gördüklerine yaltaklanan ve ancak gücü ele geçirdiğinde acımasız olan bir tiptir. Ancak çelişik bir tip olarak Murtaza yaşamı, doğruluk anlayışı, değer yargıları ve görev ahlakı ile Haybeci'den ayrılır. Murtaza'nın tüm romana hâkim olan çelişik karakterini Ali Özgentürk, romandan uyarladığı filmin hemen giriş sekansında vurgular. Özgentürk'ün uyarlaması Tunç Başaran'ın uyarlamasının aksine izleyiciye Bekçi Murtaza'yı doğrudan tanıtacak bir sekansla açılır. Onun hakkında söylenen ilk şey "tam bir bela" olduğudur. Ancak tıpkı kendisi gibi, hakkında söylenenler de çelişkilidir: "Tuhaf bir adamdı"; "Bize zararlıydı"; "Sorumluluğunu bilen, saygılı ve çok faydalı bir elemandı"; "İyi bir adamdır, çocuklarına düşkündür, para-pul düşünmez"; "Muhbirdir, yaltakç1dır"; "Kadınları sevmezdi, sözümüze-sohbetimize düşmandı"; "Namuslu, iyi bir adamdır lakin bilmez menfaatini (...) Fakirdir ama çok namusludur"; "Heykel yaklaştıkça, adam uzaklaştıkça büyür!”; "Valla-billa bizim gibi bir adamdı". Bu çelişkiler, Murtaza'nın çalıştı̆̆ fabrikadaki ilişkilerde görünür hale gelen, dönemin toplumsal dönüşümlerine uyum sağlayamamasından, daha doğrusu bu dönüşümlere uyum sağlamayı reddetmesinden kaynaklanir.

Fabrikalar, toplumsal dönüşümlerden kaynaklanan sorunların görünür hale geldiği yerlerdendir. Fabrikaların ve fabrikalarda gerçekleştirilen üretimin temel ilkelerinden biri verimliliktir. İlk kez Frederick Winslow Taylor tarafindan ortaya konan ancak en mükemmel halini Henry Ford tarafından faaliyete geçirilen üretim bandı ile alan bu ilke, zamanın verimli kullanılması, zamandan tasarruf edilmesi, üretimin hızlandırılması 
gibi amaçları ve sonuçlarıyla kapitalist toplumları açıklamada önemli bir yerde durmaktadır. Bununla beraber, çok sayıda işçinin çalıştığı fabrikaların, atölyelerin ya da diğer işliklerin askeri bir düzen içinde örgütlenmesi de önemlidir. Bu nedenle tıpkı askeri birliklerde olduğu gibi fabrikalarda da takım şefleri, vardiya çavuşları, kolcular ve de bekçiler vardır. Bu bakımdan, Bekçi Murtaza'nın öykündüğü dedesinin bir asker olmasıyla, yaptığı işlerin bir bakıma dönüştürülmüş askerlik olması hem roman hem de filmler için önemli bir tartışma noktası sağlayabilir. Verimlilik, askeri düzenle sağlanır ve askeri disiplinle kontrol edilir. Bu düzenin görünümlerini ve ona yöneltilen eleştirileri, hemen ilk yıllarından itibaren sinemada da görmekteyiz. Örneğin René Clair'in, üretim bandına uyum sağlayamayan kahramanı Émile, À Nous la Liberté'de (Bizim İçin Özgürlük, 1931) montaj hattında büyük bir akıl kaybı yaşayarak şaşkınlığa ve mizaha neden olur. Kısa bir süre sonra Amerika Birleşik Devletleri'nde, sinema tarihindeki en büyük modern kapitalizm eleştirilerinden biri gerçekleştirilir. Charlie Chaplin, Modern Times (Modern Zamanlar, 1936) adlı filminde üretim bandının hızına ve bu hızla birlikte değişen yaşam şartlarına bir türlü uyum sağlayamayan işçiyi başarıyla canlandırır. İşçinin üretim bandı üzerinde ve verimlilik ilkesine göre düzenlenmiş fabrika uzamındaki durumu zaman zaman trajikleşen bir farsa dönüşür. Neredeyse aynı trajik durumu Ali Özgentürk'ün uyarlamasında defaten yaşarız. Ancak özellikle gerçekliğinden asla emin olamadığımız ama bu olasılıktan da hiç şüphe etmediğimiz, bir gündüz düşü şeklinde tezahür eden, işçilerin süpürgeleri kuşanarak, adeta birer silahmışçasına omuzlarına vurarak fabrika avlusunda uygun adım yürüdükleri sekans önemlidir. Bir yandan, bu sekansta işçilerin birer askermişçesine uygun adım yürümeleri mütehakkim düzene işaret eder ancak diğer yandan süpürgeleri kuşanarak adeta düzenle alay edercesine yürümeleri bu mütehakkim düzenin artık geride kaldığını da imler. Bu, tragedyanın içinde vuku bulan bir farstır.

Murtaza, yıkılmakta olan düzenle kurulmakta olanın çatışmasında varlığını bulan bir tiptir. Modernlikle birlikte sadece işliklerin değil, tüm bir toplumun adeta askeri bir düzen içinde örgütlenmesi, değişimin arkasında yatan yapısal güç olmuştur. Oysa İkinci Dünya Savaşı'nın ardından Max Weber'in ilkelerini ortaya koyduğu bu toplumsal yapının (demir ka$f e s)$ ciddi bir dönüşüme uğraması önemli toplumsal sorunları doğurmak- 
tadır. Bunlar, kapitalizmden esnek kapitalizme geçiş döneminin sorunlarıdır (Sennett, 2008, 2010, 2011). Richard Sennett, tüm sorunlarına rağmen kapitalist sanayi toplumunda insanların uzun süreli ilişkiler ve kalıcı hedefler sayesinde kendilerini güvencede hissettiklerini söyler. İnsanlar çok çalışmakta, sebat etmekte ve öyle ya da böyle emekliliklerini güvence altına alacaklarını bilmektedir. Bu güvence, mevcut düzenin sürdürülmesinin anahtarıdır. Sennett (2008, s. 104), "bu tür bir iş etiği, çalışmanın mükâfatının ertelenmesini mümkün kılacak ölçüde istikrarlı kurumlar gerektirir" demektedir. Michael Haneke'nin bir alegorisi bu durumu gayet iyi açıklar: "Esirler serbest bırakıldıktan sonra çoğu eski efendisini özlüyor: 'Hiç olmazsa o zaman ne yapmam gerektiğini biliyordum'”' (aktaran Assheuer, 2008, s. 117). Bir düzenin yıkılıp bir diğerinin kurulmasındansa, köleliğe tutunmanın psikolojisi budur. Sennett (2008, s. 104), yeni kapitalizmin kültürünün böyle bir ortamda açığa çıktığını söyler: "Zamanın oku kırıldı artık; sürekli olarak yeniden tasarlanan, rutine düşman olan ve kısa vadeye odaklı bir politik ekonomide hedefine varamaz oldu bu ok. İnsanlar uzun süreli insani ilişkilerin ve kalıcı hedeflerin yokluğunu hissediyor." Yeni kapitalizmle birlikte işliklerde bireyin merkezde olduğu bir düzen yıkılmış, bireyin yerini topluluk almış ve öznenin kaderi topluluğun eline terkedilmiştir. "Takım çalışması" denilen olgu budur:

"Bireyi değil grubu esas alan bir etik olan modern takım çalışması, kişinin yücelmesine değil üyeler arasındaki karşılıklı uyuma vurgu yapar. Takımlarda zaman esnektir ve onyıllar süren uzun bekleyişlere göre değil, belirli ve kısa süreli görevlere göre ayarlanır. Ancak takım çalışması, beraberinde modern işyerini hâkimiyeti altına alan sı̆̆ ilişkileri getirir. Takım çalışması, tragedyanın alanından çıksa da, insan ilişkilerini bir farsa dönüştürür" (Sennett, 2008, s. 112).

Hem romanda hem de film uyarlamalarında tanıklık ettiğimiz, işçilerinin Murtaza'yı alaya alma güdülerinin altında bu durum yatar. Artık işliklerde varlık gösterebilmek için takımın içinde yer almanız gerekmektedir. Ne var ki takım, kendisini oluşturan bireylerin toplamından daha fazla çürümüş ve neredeyse tüm ahlaki ilkelerini yitirmiştir. Murtaza'nın da fabrikada tutunması için dönüşmesi ve insan ilişkilerini farsa çeviren bu oyuna dâhil olması gerekmektedir. Ancak o, keskin bir biçimde eski düzenin insanıdır ve dönüşmeyi reddetmektedir. 
Fabrika işçilerinin Murtaza'yı defaten alaya almaları ve onunla eğlenmeleri çok eski bir çatışmayı anımsatır. Bu, insanlık tarihinin en eski ikiliklerini akla getiren bir çatışmadır aslında. Disiplin ve başıbozukluk, düzen ve kargaşa, ciddiyet ve ciddiyetsizlik ya da yas ve şenlik fabrikada tanıklık ettiğimiz çatışmanın arka alanında mevcuttur. Bu açıdan fabrika, Pieter Bruegel'in 1559 yılında tamamladığı Karnaval ve Perhiz Arasındaki Savaş adlı tablosuna benzer. Bu tablo, Avrupa halk kültürlerinde çok önemli bir yeri olan şenliği ve bu şenlikle sürekli çatışma halinde olan disiplini konu alır. Halk, dönemin Flaman kasabalarından birinin meydanında toplanmıştır ve bir şenlik vuku bulmaktadır. Fıçının üzerine oturmuş şişman bir adam olarak sembolleştirilmiş karnaval, elindeki şişe geçirilmiş domuz etiyle, bir rahip ve bir rahibenin çektiği arabada, elindeki fırıncı küreğinin üzerindeki iki balığıyla oturan ve yine bir rahibe olarak sembolleştirilen perhize karşı savaşmaktadır. Alegori ve sembollerle yüklüdür tablo; bir yanda tüm düzensizliği ve neşesiyle gündelik hayat diğer yanda ise hem bu hayatı hem de toplumu ve özneyi disiplin altına almaya, düzene ve hatta sıkıdüzene tabi kılmaya çalışan yüksek otorite yer almaktadır. Bruegel'in eserine kamusal ve özel hayatın tüm çelişkileri ve çatışmaları yansır. Neşeyle sürdürülmek istenen, Dionysosçu bir hayata karşı Apollucu bir disiplin ve kaçınılmaz bir biçimde disipline eşlik eden öfke. Tarih boyunca böyle olmuş, öfke ve disiplin hep kol kola yürümüştür. Oysa neşe çoğu zaman bir esrimeyle gelir ve kaotiktir; düzeni yıkan bir yönü vardır. Bu açıdan Murtaza, neşe ve disiplin arasındaki kadim mücadeleyi yansıtan bir romandır. Romanın her iki uyarlamasında da işçilerin neşesi dikkat çekici bir biçimde Bekçi Murtaza'yı öfkelendiren yıkıcı-düzen bozucu bir eylemdir.

Değiş̧en düzene karşı Murtaza sanki bir bekçi değil de Türkiye Cumhuriyeti'ni toptan disiplin altına almaya çalışan bir memurdur. Onu tanıyanların ifadesiyle kraldan daha kralcıdır. Aslında Murtaza, Etienne de La Boétie'nin neredeyse modernlik öncesi dönemde tanımladığı biçimiyle, gönüllü bir kuldur. Boétie, 1548'de yazdığı Gönüllü Kulluk Üzerine Söylev'inde Murtaza gibi, iktidarın eli-ayağı olagelenleri şöyle eleştirmektedir: "Eğer siz vermediyseniz, sizi gözetlediği bu kadar gözü nereden buldu? Sizden almadıysa, nasıl oluyor da sizleri dövdüğü bu kadar çok eli olabiliyor? (...) Sizin tarafınızdan verilmiş olmasa üzerinizde nasıl iktidarı olabilir?" (Boétie, 2011, s. 25). Bekçi Murtaza kimi zaman amirlerini 
dâhi bezdirecek biçimde, iktidara rağmen iktidarın kuludur. Ali Özgentürk'ün uyarlamasında işçilerin dikkat çekici bir repliği vardır: "Düşürürseniz elinizden kırbacı, geçer kırbaç bizim elimize." Murtaza, iktidarın elindeki kırbacın düşmemesi için çabalayan bir kuldur. Tekrar etmek gerekirse, Murtaza'nın bu çelişik kişiliği temel olarak kendi döneminin insanı olmamasından kaynaklanmaktadır. 1925'ten sonra mübadeleyle Balkanlar'dan gelip Çukurova'ya yerleşen Murtaza, aslında dedesi Kolağası Hasan Bey'in yaşadığı bir zaman ve mekânda sıkışıp kalmıştır. En yakınları için yıkıcı olsa dâhi mutlak bir dürüstlük, göreve bağlılık ve çıkar ilişkilerini göz ardı etmek, aslında geride kalmış bir dönemin değerleridir. Bütün bu çelişkiler ve Murtaza'nın yaşadığı zamanın ve mekânın insanı olmayışı aklımıza hemen Miguel de Cervantes'in Don Quijote'unu getirir. Her iki uyarlamada da yer almamasına karşın, Orhan Kemal'in romanında Emniyet Müdürü ve Fen Müdürü, Bekçi Murtaza hakkında konuşurken onun Don Quijote'luğunu vurgularlar:

"- Deli bu be... ha?

- Belki tam deli değil. Şu hani bir şövalye vardı... İspanyol..."

- Evet, Don Kişot...

- Don Kişot'a benziyor..." (Kemal, 2015, s. 98).

Bu açıdan Bekçi Murtaza Cervantes'in Don Quijote'una denk düşerken, Gurbet Kuşları'nın Haybeci'si ise tahmin edileceği gibi, Sancho Panza'ya karşllık gelmektedir. Don Quijote ve Sancho Panza'nın arasındaki karşıtlık ilişkisine benzer biçimde Bekçi Murtaza ve Haybeci arasında da bir karşıtlık ilişkisi vardır. Haybeci, Bekçi Murtaza'nın anti-tezidir.

Bekçi Murtaza'nın yaşadığı dönemin insanı olmamasına dair önermeler, hem romanın yazıldığ 1 hem de filmlerin uyarlandığı dönemin belki de en önemli tartışmalarından olan sınıf mücadelesine romanda ya da filmlerde yer verilmemesiyle de gerçekleştirilir. Ne Bekçi Murtaza'nın, ne de romanda ve filmlerde irdelenen diğer karakterlerin hiç birinin sınıf bilinci yoktur. Bekçi Murtaza hâlihazırda Karl Marx'ın eleştirilerini yönelttiği, kapitalistin eli-kolu olan ustabaşlara denk düşerken, fabrikadaki işçiler de sınıf bilincine sahip olmayan lümpen proleterlerdir. Bu durumu şöyle yorumlamak mümkündür: Orhan Kemal'in de bizatihi Millî Mensucat Fabrikası'nda çalıştığı yıllarda Adana, son derece yoğun göç alan bir şehirdir. Şehre akın eden bu insanların ilk ve en önemli amaçları ise iş bulmak ve şehirde tutunmaktır. Bu nedenle “Orhan Kemal'in romanlarında toprak 
ve fabrika işçileri iş bulma zorunluğu ile her türlü güçlüğe boyun eğen kişiler olarak görünürler (...) Aralarında eski, deneyimli işçilerden, namuslu ustabaşılarından yararlanarak kişiliklerini bulanların yanı sıra, küçük çıkar hesaplarına dayanan o berbat, acımasız dünyanın çarklarına kapılanlar vardır. Bu çıkar hesaplarının, gizli oyunların özünü kavrayacak bilinç düzeyine erişemeyen mevsimlik işçiler, deneyimsizler, sarı işçi durumuna düşer" (Kurdakul, 1983, s. 4). Bu durum sadece romanda değil Tunç Başaran'ın gerçekleştirdiği uyarlamada da görülmektedir. Ama romanın ve Başaran'ın uyarlamasının aksine, Ali Özgentürk'ün uyarlamasında yer alan, bir işçinin ölümüyle başlayan ve arkadaşları tarafından gömülmesiyle devam eden gerçeküstü sekans, işçi sınıfına, sınıf bilincine ve işçi sınıfının örgütlenmesine dair önemli bir göndermedir. Ancak bu durum filmin geneline yayılmaz.

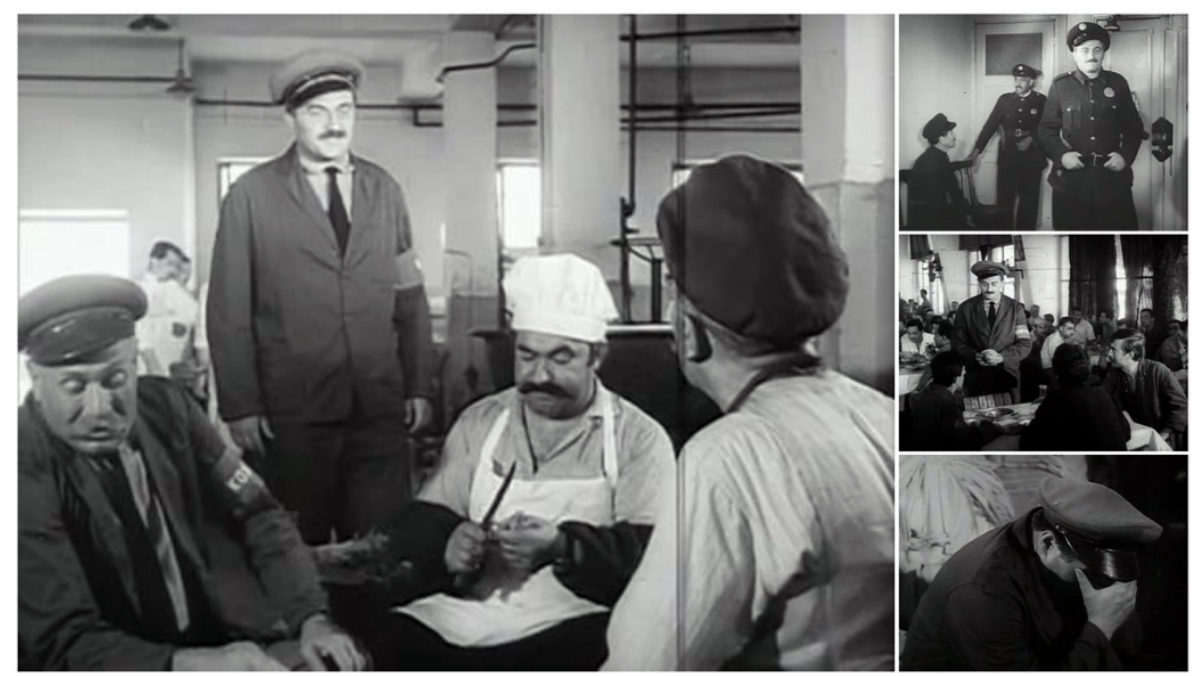

Resim 1: Orhan Kemal'in Murtaza adlı romanından Tunç Başaran tarafından Bekçi Murtaza (1965) adıyla sinemaya uyarlanan filmden çeşitli sahneler.

Orhan Kemal'in romanlarında çocuklar, genç kızlar, toplumsal bozulmanın ve sorumsuzluğun acı meyveleri görünüşündedir (Kurdakul, 1983, s. 4). Bu duruma Murtaza'da da tanıklık ederiz. İş yaşamında adeta bir despot olan Murtaza, özel yaşamında ise tam tersine, ailesinin dirliğini 
sağlamaktan acizdir. Eşi, her daim vazifesi kadar eviyle de ilgilenmesi gerektiğinden yakınır. Dedesi Kolağası Hasan Bey'in adını verdiği oğlu Hasan -bu karakter film uyarlamalarında yoktur-, Murtaza'nın büyük hayallerinin aksine bir yalancı ve hırsıza dönüşür. İzmirli bir zenginle evlendirmek istediği Selma/Emine kendinden çok daha büyük olan bir muhasebeciye kaçar. İşbaşında uyuyakalan küçük kızı Firdevs/Cemile’nin ölümüne bizatihi kendisi neden olur. Bütün bir toplumu düzene sokmaya çalışan Murtaza, aslında iki yakasını bir araya getirmekten, kendi ailesini derleyip toparlamaktan aciz bir katildir. Dikkat çekici bir biçimde, Tunç Başaran'ın uyarlamasında yer alan Selma'nın aksine Ali Özgentürk'ün uyarlamasındaki Emine, çok güçlü bir kadındır. Murtaza, onu ve sevdiği adamı bir gecekonduda bastığında karşısına dikilerek sorgular ve kovar.

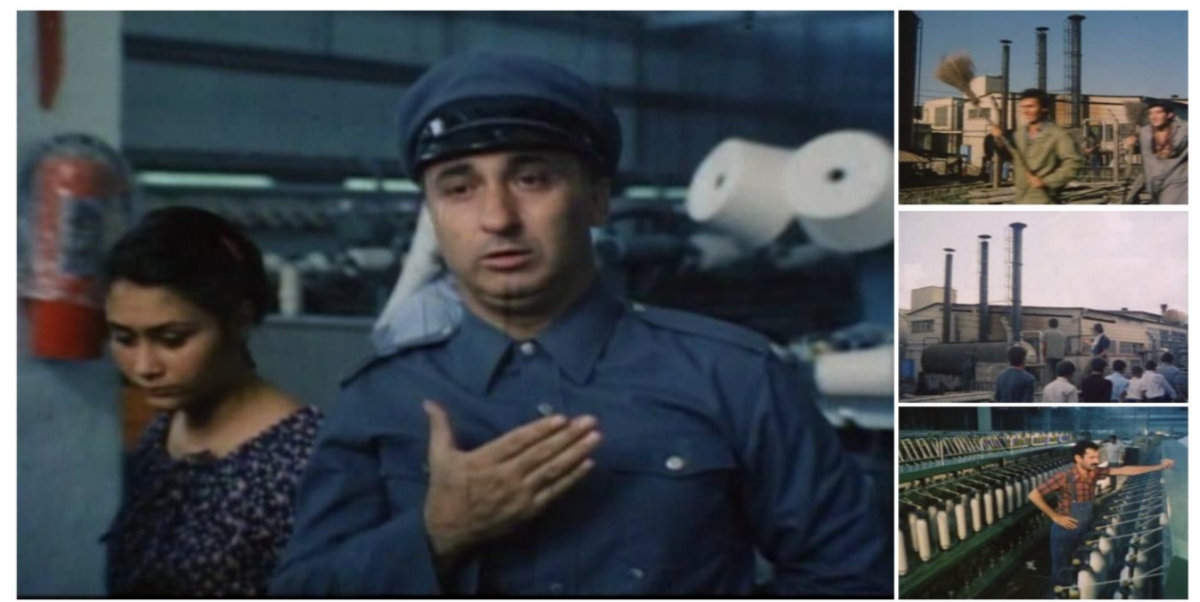

Resim 2: Orhan Kemal'in romanından Işıl Özgentürk tarafından senaryolaştırılan ve Ali Özgentürk tarafindan Bekçi (1985) adıyla sinemaya uyarlanan filmden çeşitli sahneler. Tunç Başaran'ın uyarlamasında Murtaza Müşfik Kenter tarafından canlandirılmaktayken bu filmde Müjdat Gezen tarafindan canlandirlmaktadır.

Tüm bunları da romanın ve uyarlamalarının işaret ettiği, toplumsal dönüşümlerin yol açtı̆̆ı sorunların belirtileri olarak değerlendirebiliriz. Murtaza gibi, yeni düzeni radikal bir biçimde reddeden bir tipin dahi en yakınındaki kişiler, hatta ailesinin üyeleri yeni düzene uyum sağlamış durumdadır ve hatta Murtaza' yı bu düzenin dışında kaldığı için eleştirmek- 
tedir. Romanda ve filmde, Murtaza'nın eşinin ve çocuklarının onu bu nedenle kıyasıya eleştirdiklerini ve hatta fabrikadaki işçiler gibi zaman zaman alaya aldıklarını görürüz. Murtaza, mevcut düzende kendi ailesine dahi bir yabancı olmuştur.

\section{Genel Değerlendirme ve Sonuç}

Yaşar Kemal (12 Haziran 1970, s. 2), "Murtaza, bizim edebiyatımızın her yönüyle bütün çelişkileriyle, iç ve dış çelişkileriyle insan olabilmiş, belki de tek tipidir" der ve Murtaza' nın çelişkilerini hasta olmasına bağlar. Murtaza bir yandan kendine, çocuklarına, ailesine ve çevresine yabancılaşmıstır ve kraldan çok kralcı davranırken en yakınlarını dahi umursamamaktadır. Diğer yandan ise tüm bunları aslında idealleri için yapmaktadır, dürüst ve ahlaklıdır. Bir bakıma, kendisini çevreleyen yozlaşmanın içinde ahlaki değerlerin savunusunu yapmaktadır. Kemal'e göre bu çelişkilerden Murtaza'nın hastalandığı sonucunu çıkarabiliriz: “Murtaza hastalanmıştır. Milyonlarca insan hastalanmıştır, ama ortada hastalanmayan, hastalanmayacak olan bir yön de kalmıştır. İnsanlığın hem umutsuzluğudur Murtaza, hem de umududur" (Kemal, 12 Haziran 1970, s. 2). Tam da bu anda şöyle bir itirazı ortaya koyabiliriz: Evet, Murtaza pek çok açıdan tutarsız ve çelişkilerle dolu bir tiptir. Hatta bu çelişkiler romanı okuyan ya da uyarlamaları seyreden bizlere de sirayet eder ve bazen gülerek bazen de ağlayarak okur-izleriz. Hem romanda hem de uyarlamalarda trajedi ve fars iç içe ilerler. Ne var ki, bu çelişkilerin ve tutarsızlıkların müsebbibi Murtaza değildir. Murtaza, Yaşar Kemal'in ortaya koyduğu biçimde, bir hasta değildir. Onun hastalığı içsel bir nedenden kaynaklanmaz, tamamen dışsaldır. Yaşadığı zamanın ve uzamın çelişkileri ve tutarsızlıklarıdır. Bu bakımdan tıpkı Don Quijote gibi, Murtaza da değişen toplumsal yapının, insan ruhunu zedeleyen sonuçlarının bir kurbanıdır. Evet, Don Quijote da bir yanıyla budaladır ama diğer yanıla gülünç duruma düşme pahasına toplumun değişimine direnen, aklın, mantığın, teknolojinin, kapitalizmin değil, saf insanlık halinin yanında duran bir karakterdir (Kıraç, 27 Ocak 2012). Hasta olan Murtaza değil, onu tahakküm altına almaya ve kendisine benzetmeye çalışan toplumdur.

Orhan Kemal'in yapıtının Vatan Gazetesi'nde tefrika edildiği 1952'den, Ali Özgentürk'ün uyarlamayı gerçekleştirdiği 1985 yılına değin Murtaza, 
ekonomik, kültürel, politik ya da toplumsal dönüşümlerin sorunlarını güçlü bir biçimde temsil etmiştir, hâlâ da temsil etmektedir. Bu açıdan, Deleuze'ün Kritik ve Klinik'te (2013) önerdiği semptomatolojik yönteme göre değerlendirdiğimizde Orhan Kemal, Tunç Başaran ve Ali Özgentürk'ün Murtaza aracılığıyla birer hekim gibi çalıştıklarını söyleyebiliriz. Her üçü de Murtaza aracılığıyla toplumsal sorunların belirtilerini işaret eder. Murtaza'nın evde, sokaklarda ve fabrikada diğer insanlarla ve toplumla kurduğu ilişkiler bir hastalığın belirtilerini göstermektedir. Murtaza, içinde yaşadığı topluma ve doğru ya da yanlış olmanın ötesinde yaygın biçimde kabul gören değerlere yabanclaşmıştır. Bu yabancılaşmanın sonucunda da diğer insanlarla ve toplumla ilişki kuramaz durumdadır. Murtaza'nın yaşadıklarıyla, belirtilerini duyumsadığımız hastalık ve bu hastalığın nedenleri yine romanda ve uyarlamalarında ortaya konur. Yazar ve yönetmenler, hastalı̆̆ın nedenlerini doğrudan göstermeseler de okurun ve seyircinin bu nedenleri kavramasını sağlayacak durumları yaratırlar. Okur ve seyirci, Murtaza' nın yaşadıklarıyla, kapitalizminden yeni kapitalizme geçişle birlikte vuku bulan toplumsal dönüşümlerin özneyi karanlık bir geleceğe sürüklediğini görür. Böylelikle hastalığın belirtileri değerlendirilmiş ve nedenleri ortaya konmuş olur. Üçüncü aşamayı, yani yazarın ve yönetmenlerin tıpkı bir hekim gibi, hastalığın tedavisi için bir reçete önermelerini ise romanda ya da uyarlamalarında doğrudan görmeyiz. Jacques Rancière (2010, s. 65), "Bir gösteriyi seyredip de dünyayı kavramaya, entelektüel olarak kavrayıp da eylem kararı almaya geçmeyiz. Duyumsanabilir dünyadan, başka hoşgörüler ve hoşgörüsüzlükler, başka kabiliyetler ve kabiliyetsizlikler tanımlayan başka bir duyumsanabilir dünyaya geçeriz," demektedir. Gerek roman gerekse ondan uyarlanan filmler belki bize bir tedavi önermez ancak başka yaşam biçimlerine dair olasılıkların önünü de kapatmaz. Örneğin Ali Özgentürk'ün uyarlamas1nın bir sekansında Murtaza şöyle der: "Vardır çok düşmanı bu vatanın ama vardır çok Murtazalar." Bu, her şeye karşın bir olasılığın mevcudiyetini sunan bir önermedir. Nihayetinde hem edebiyat hem de sinema, dünyanın hastalığına karşı bir sağaltım olasılığını taşır. Orhan Kemal, Tunç Başaran ve Ali Özgentürk de Murtaza aracılığıyla bu olasılığı ortaya koymaktadır: Dünya bizatihi hastalığın kendisidir. Ama aynı zamanda umudun kaynağı da odur. 
EXTENDED ABSTRACT

\title{
Reading and Watching Murtaza, As a Symptom of the Social Problems
}

\author{
Aydın Çam \\ Çukurova University
}

In this study, Orhan Kemal's novel Murtaza, which is firstly published serially by Vatan Newspaper in 1952, later published as a book by Varlik Publishing House in the same year; and two films adapted from the novel, Tunç Başaran's Bekçi Murtaza (Murtaza the Watchman, 1965), and Ali Özgentürk's Bekçi (The Watchman, 1985) are inquired by focusing on Murtaza stereotype. Murtaza, whom has the power to represent a society and an era, together with the oddities of a human type, differs from the ordinary characters. This is a situation that exceeds the character traits that generally limited to the individual properties. Moreover, for Murtaza, the boundaries of its representation are so wide that it is not specific to a particular geography or an era. Murtaza is a universal stereotype, and according to Yaşar Kemal (1970, June 9) he is "one of the most interesting types of the literature, one of a real immortal types". However, Murtaza is a social type. Social types are the structural elements that enable us to understand a specific geography, an era, or a community. And, they are not only functional for literature. For instance, for philosophers or social scientists, social types are at the centre of their analysis. That is why almost every great litterateur has created a stereotype that suffers from anomalies and perversions of the world. The symptoms of social problems become visible with these types. Just as Karl Marx's proletariat, Georg Simmel's stranger and C. Wright Mills' white collar, all these stereotypes have social equivalents. And also these stereotypes refer to economic, political, cultural and social problems too.

According to Gilles Deleuze (2013, p. 12), the world is made up of symptoms, and the author is a clinician, whom isolates these symptoms and tries to treat them. From this viewpoint Murtaza, the novel and the 
adaptations are analysed by making a methodological contact with literature, cinema, and medical sciences in the study. Litterateurs and filmmakers can investigate the society just as a clinician diagnoses the diseases. An author or a director may watch the disease symptoms, identify the problems, diagnose the social diseases, and give therapy recommendations by following the symptomatology, etiology, and therapy practices. In addition to this, the contextual film analyse method (Phillips, 2000; Elsaesser \& Buckland, 2002; Barsam \& Monahan, 2010; Corrigan \& White; 2012; Nelmes, 2012; Ryan \& Lenos, 2012) is also used in the study, especially for adaptations.

Murtaza is the fictitious character of the novel, inspired by Adana city that seriously transformed by industrialization in the 1950s, and he is also a victim of these changes. The time in which Orhan Kemal wrote Murtaza is the years of transformation by the economic structural changes in Çukurova. In this era, the traditional/conventional capitalist relations have been replaced by new capitalist/conventional relations in the city. In addition to this, agricultural production increased and industrial enterprises where agricultural products were processed began to intensify in the region. People living in the rural areas of Çukurova and nearby regions, have moved towards the city centers; consequently, transformations in social relations began to take place at different scales. One way or another, these are all structural transformations. These is the disintegration that occurs in different scales but which in some way concerns the individual and the society in which it belongs, which leads to changes, transformations and often conflicts in the conventional structure. As asocial stereotype, Murtaza coexists with this extremely dynamic transformation in the city. Murtaza is a stereotype that finds its existence in the conflict of the orders, those one is collapsing and the other one is being established. This conflict not only creates tragedies but also farce. This situation lies beneath the motives of the factory workers that we witness in both novel and film adaptations.

The way to avoid this farce is to adapt to society. Now you need to be in the team to be active in the workshops. However, the team has lost almost all of its moral principles. It is degenerated and much more immoral than the sum of its individuals (Sennett, 2008, 2010, 2011). Murtaza should also be transformed and must be involved in this game that translates human relationships into farce, to stay in the factory. But he is strictly the 
person of the old order and refuses to be transformed. Even members of his family those who are closest to Murtaza, a stereotype that radically rejects the new order, have adapted to it. Even his family has criticized Murtaza for staying out of this order. In the novel and adaptations, we see that Murtaza's wife and children criticized him mercilessly and even made fun of him sometimes just as factory workers did. Murtaza has been aliened even to his family in the current order. He is an alienated person, who cannot accommodate the space and time, and cannot fit into society.

Following the analyses, it is appeared that the anomalous character and inconsistent life of Murtaza, is actually the symptom of social problems, which is formed by transformations of capitalist industrialization. Orhan Kemal, Tunç Başaran, and Ali Özgentürk diagnose the social diseases by Murtaza. And even though there aren't any therapy recommendations given by author and/or directors in their works, there is still a possibility for the therapy of society.

\section{Kaynakça / References}

Assheuer, T. (2008). Yakın plan Haneke. N. Pakkan (çev.), İstanbul: Agora Kitaplığı.

Barsam, R. M. \& Monahan, D. (2010). Looking at movies: An introduction to film (3. Bask1). Londra: W. W. Norton \& Company.

Binyazar, A. (1970). Orhan Kemal öldü Murtazalar yaşayacak. Türk Dili Dil ve Edebiyat Dergisi, 22(226), 278-284.

Boétie, E. (2011). Gönüllü kulluk üzerine söylev (3. Baskı). M. A. Ağaoğullar1 (çev.), Ankara: İmge Kitabevi.

Corrigan, T. \& White, P. (2012). The film experience: An introduction (3. Bask1). Boston \& New York: Bedford / St. Martin's.

Deleuze, G. (2013). Kritik ve klinik (2. Bask1). İ. Uysal (çev.), İstanbul: Norgunk Yayınları.

Elsaesser, T. \& Buckland, W. (2002). Studying contemporary American film: A guide to movie analysis. New York: Oxford University Press.

Hizlan, D. (9 Haziran 1970). Büyük usta. Yeni Gazete. 
Hinderink, J. \& Kiray, M. B. (1970). Social stratification as an obstacle to development - a study of four Turkish villages. New York: Praeger Publishers.

Kemal, O. (2015). Murtaza (22. Bask1). İstanbul: Everest Yayınları.

Kemal, Y. (12 Haziran 1970). Orhan Kemal, umut ve aydınlık. Cumhuriyet Gazetesi, 2.

Kemal, Y. (9 Haziran 1970). Yaşar Kemal, Orhan Kemal'i anlatıyor. Yeni Gazete.

Kıraç, R. (27 Ocak 2012). Don Kişot'la kanundışı yaşamak... Radikal Kitap Eki.

Kurdakul, Ş. (1983). Orhan Kemal'in insanları. Yazko Somut - Haftalık Sanat ve Kültür Dergisi. Say1: 44(18), 4.

Nelmes, J. (Ed.). (2012). Introduction to film studies (5. Bask1). Londra \& New York: Routledge.

Özcanll, N. (Koordinatör) (2008). Adana sanayi tarihi. Adana: Adana Sanayi Odası Yayınları.

Phillips, P. (2000). Understanding film texts: Meaning and experience. Londra: BFI.

Rancière, J. (2010) Özgürleşen seyirci. E. B. Şaman (çev.), İstanbul: Metis Yayınları.

Ryan, M. \& Lenos, M. (2012). Film çözümlemesine giriş - Anlatı Sinemasında Teknik ve Anlam. E. S. Onat (çev.), Ankara: De Ki Yayınları.

Sennett, R. (2008). Karakter aşınması - Yeni Kapitalizmde işin kişilik üzerindeki etkileri (3. Baskı). B. Yıldırım (çev.), İstanbul: Ayrıntı Yayınları.

Sennett, R. (2010). Kamusal insanın çöküşü (3. Baskı). S. Durak \& A. Yılmaz (çev.), İstanbul: Ayrıntı Yayınları.

Sennett, R. (2011). Yeni kapitalizmin kültürü (2. Bask1). A. Onacak (çev.), İstanbul: Ayrıntı Yayınları.

Smith, D. W. (2013). Saf IÇKIN YAŞAM - Deleuze'ün "Kritik ve Klinik" Projesi. E. Koyuncu (çev.), İstanbul: Norgunk Yayınları.

TÜIKK - Türkiye İstatistik Kurumu. Çevrimiçi Erişim: http://www.tuik.gov.tr.

Uğurlu, N. (1973). Orhan Kemal'in ikbâl kahvesi. İstanbul: Cem Yayınları.

Yaman, Y. (Koordinatör) (1981). Yurt ansiklopedisi - Türkiye İl İl: Dünü, Bugünü, Yarını Cilt I. İstanbul: Anadolu Yayıncılık A.Ş. 
Aydın Çam

Kaynakça Bilgisi / Citation Information

Çam, A. (2019). Murtaza'yı toplumsal sorunların belirtisi olarak okumak ve izlemek. OPUS-Uluslararası Toplum Araştırmalar Dergisi, 10(17), 2056-2077. DOI: 10.26466/opus.517860 